\title{
The quest for mediterranean bioethics
}

\author{
Ana Borovecki
}

Published online: 6 September 2012

(C) Springer Science+Business Media B.V. 2012

This thematic issue of the Journal of Medicine, Health Care and Philosophy is dedicated to the Mediterranean bioethics or as the title says to the quest for it. Recently, I came across an article written by a Croatian moral theologian and bioethicist Tonči Matulić entitled "Researching the Roots of Mediterranean Bioethics- the Ethics of Virtue and Happiness as a condition sine qua non" (Matulić 2007). This article tried to answer the following questions: Is there such a thing as regional Mediterranean bioethics at all and what are its foundations? Who are proponents of this approach? What is the relationship between Mediterranean bioethics and other regional approaches to bioethics that come from the same cultural background that of a western cultural circle but who differ methodologically and epistemologically from the Mediterranean bioethics? What are specific historical roots of Mediterranean bioethics and their relationship in connection to the human being and society? Is there something to be drawn from the Mediterranean bioethics that can bring a novelty to today's development of our scientifically and technically oriented societies? Matulić in his paper gives the following answers to the previously posed questions: The idea of Mediterranean bioethics was born in Spain in Madrid. The first one to mention this term was Diego Gracia Guillén (1989). His idea of Mediterranean bioethics is connected to his radical critique of mainly Anglo-Saxon bioethical approaches. The proponents of the idea of Mediterranean bioethics are those institutions (academic or scientific) and those bioethicists who come from Mediterranean cultural circle and who are

A. Borovecki $(\square)$

Anadrija Stampar School of Public Health, School of Medicine, University of Zagreb, Rockefellerova 4, 10000 Zagreb, Croatia e-mail: abor@mef.hr by their mode of education dedicated to the values of Mediterranean traditions and the way of life, views on health and healing, ethics of virtue, sanctity and quality of life, transcendence and spirituality. The idea of Mediterranean bioethics is from its beginning extremely critical towards any radical confrontations with other cultural models within the field of bioethics. The idea of Mediterranean bioethics aims to promote a dialog and pave the way towards logical and value-oriented bonding between classical tradition of virtue ethics and modern deontological approaches encompassing in its discussions important elements of critical historical evaluation of both approaches. Ethics plays a central role in the idea of Mediterranean bioethics based on the virtue of friendships as the foundation of any quality interpersonal relationship. Such approach of interpersonal relationship is not based on procedures and contracts but on the trust that we have for each other as human beings. Matulić then concludes that although Mediterranean bioethics is still in development it can offer constructive solutions to the reign of ethical relativism especially in the area of the ethos of citizens. It can also be used as a tool against the rule of ideology of technicism. Finally it can be especially important for the clinical medical practice (Matulić 2007).

Although, this article was written in 2007 some of its conclusions especially those connected to the ideas of different approaches to the societal ethics lately became important for the Mediterranean region, especially the Middle Eastern and African part. Recently, we have been witnesses of extreme societal changes in these parts of Mediterranean region which will have a huge impact on the world as we know it.

This issues starts with the article written by Pierre Malia from Malta (a country in the heart of Mediterranean). It is a sort of introduction into the issue of Mediterranean 
bioethics with possible predictions for future developments and Maltese experiences. Malia in his contribution reflects in dialog on Diego Gracia Guillén's positions and other authors' positions on Mediterranean bioethics expressing his belief in the existence of specificity of bioethical approach that can be found in the Mediterranean region.

The second contribution in this issue is the one of Slavinio Leone from Italy, from Palermo, Sicily, from The Institute of Bioethical Studies named after Salvatore Privitera (1945-2003) (Privitera 1996), after Diego Gracia Guillén, the second important proponent of the idea of Mediterranean bioethics. Leone in his contribution elaborates his main ideas about the features of Mediterranean bioethics basing his arguments in historical analysis of the roots of Mediterranean bioethics that are connected to its philosophical and religious heritage as well as healing practices.

The third contribution comes from Spain from Borja Institute of Bioethics in Barcelona. The authors of this contribution talk about their views on bioethics within Mediterranean culture and Spanish experiences. This contribution again reaffirms the position of the importance of Mediterranean approach to bioethics.

The fourth article comes from Croatia offering story about genesis of one approach to bioethics present today in Croatia called integrative bioethics, mainly based on continental deontological (mainly German) and Anglo-Saxon approaches with influence of left wing political ideologies, while Mediterranean is something that is only referred to as something that is marginally present and remembered from the Croatian philosophical past.

The final fifth contribution of this issue comes from Marseille, France from Espace éthique méditerrenéen. The authors are starting from the presumption that there are distinct ethical features between Anglo-Saxon liberal and
Latin (Southern Europe) paternalist ethical traditions. They have decided to measure predominance of bioethical paradigm (principalism) by comparative analysis of regional moral opinion reflected in nation-health state laws. They attempt to ascertain the extent and nature of variation between the countries with respect to understanding the application of the principle of the autonomy. Their conclusion is that there are less regional differences thus it seems that even in the Mediterranean area we find more and more combination of both Anglo-Saxon and Mediterranean features or as authors call it Southern European ethical features in bioethical debates.

As you can see from the contributions all the authors are coming from the European Mediterranean countries. I also wanted to include in this issue the authors from the Middle Eastern and African part of the Mediterranean. However, these attempts were hampered by language barriers and recent events in the region. I would also like to thank Henk ten Have, Renzo Pegoraro and Marie-Jo Thiel who helped me a lot with their suggestions for some of the contributions in this issue. I think this issue will create a lot of questions and debate among its readers because of the content and approaches proposed by some of the authors. I leave it to you dear reader to answer the question by yourself after reading this issue: Is there a Mediterranean Bioethics?

\section{References}

Gracia Guillén, D. 1989. Fundamentos de bioética. Madrid: Ediciones de la Universidad Complutense, S.A.

Matulić, T. 2007. Researching the roots of mediterranean bioethics. Filozofska istrazivanja 107: 529-550.

Privitera, S (ed.). 1996. Bioetica mediterranea e nordeuropea. Rome: ISB, Collectio Bioethica n.13, Armando Editore. 